\title{
An Investigation of the Balanced Literacy Approach for Enhancing Phonemic Awareness of Thai First-grade Students
}

\author{
Sarunya Tarat \\ Naresuan University International College (NUIC), Naresuan University, Phitsanulok, Thailand \\ Usaporn Sucaromana \\ Department of Western Languages, Srinakharinwirot University, Bangkok, Thailand
}

\begin{abstract}
This study examined the effectiveness of the balanced literacy approach in enhancing performance on phonemic awareness of Thai first-grade students. The intervention program based on the balanced literacy approach was carried out 10 weeks to support students in improving their phonemic awareness skills. Thirty students aged 6 and 7 year-old were participated in this study. Four fricative consonants were taught as the target sounds. Mixed methods were employed to collect both quantitative and qualitative data. Posttest results showed that students significantly performed better on measures of phonemic awareness. Two-week follow-up data indicated that students could retain and recall information about phonemic awareness. Additional observations of student engagement in learning phonemic awareness were also generated.
\end{abstract}

Index Terms - phonemic awareness, the balanced literacy approach, young children, L2 learners, student engagement

\section{INTRODUCTION}

Sound system is one of the first linguistic abilities that learners need to learn before other abilities are acquired (Werker \& Yeung, 2009). The phoneme is the basic unit of a language's sound system which learners need to acquire and develop to learn language skills (Bicăn, 2005). In order to learn language skills successfully, learners must become aware of phonemes. Phonemic awareness has been defined in different ways. For example, it has been defined as a skill to detect the individual phonemes of words, identify their characteristics, and manipulate those phonemes (Justus, Mahurin \& Robinson, 2011). However, Cunningham (1988) argued that phonemic awareness should mean the ability to examine language and then manipulate the component sounds of spoken language (Griffith \& Olson, 1992). In particular, it is the ability to manipulate the individual phonemes of a word by breaking the word down to its spelling and blending the phonemes to read (Behan, Dunbar, Dunn, Ferguson, Gray, \& Mitchell, 2007). Some researchers think that phonemic awareness is the understanding that words are made up of a set of individual sounds (Deureen \& Reading, 2007; Gillon, 2005; Yopp, 1992).

Regarding to language learning, phonemic awareness is important because it enables learners to think about and know how to manipulate phonemes of words in order to read, spell, or write (McCulloch, 2000). Several researchers demonstrated that phonemic awareness relates to reading ability (Carlson et al., 2003; Deureen \& Reading, 2007), spelling ability (Caravolas, Hulme, \& Volín 2005; Griffith, 1991) and writing ability (Griffith \& Olson, 1992). Tankersley (2003) regarded phonemic awareness as an indicator of learners' ability to learn reading. Before learning to read, learners need to learn, recognize, and understand that words consist of individual sounds that are represented by letters or groups of letters (Zeece, 2006). This awareness enables learners to understand the relationship between sounds and letters and to use this relationship to read even if they have never seen those words before (Griffith \& Olson, 1992).

Additionally, phonemic awareness is also related to spelling ability. Researchers studied this correlation and found that learners know how to spell if they possess and have adequate phonemic awareness (Caravolas, Hulme, \& Volín 2005; Griffith, 1991). Juel et al. (1986) further stated that this awareness helps learners to understand and use the correspondence between sounds and letters to spell (Eldredge, 1995). In addition, Lundberg, Frost, and Peterson (1988) investigated the use of phonemic awareness activities to accelerate the phonemic awareness of kindergarten children and found that participants who had learnt through such activities could develop their awareness and achieved better scores than those who did not (Griffith, 1991).

Furthermore, phonemic awareness also relates to writing performance because the acquisition of phonemic awareness and alphabetic principles are correlative. In other words, this awareness enables learners to recognize the letters of writing systems and understand how to write words and sentences (Bosman, Graaff, Hasselman, \& Verhoeven, 2009). As a result, children who possess and develop phonemic awareness can do writing tasks better than those who do 
not because this awareness supports them to understand sound-letters correspondence and know how to write words correctly.

Phonemic awareness inadequacy is an obstacle in learning language abilities. For example, Harm, Ross, and Ukrainetz (2009) investigated reading abilities of children with low phonemic awareness and found that these children have more difficulty than children who have adequate phonemic awareness because inadequate phonemic awareness decreases the ability to acquire word decoding, resulting in reading difficulties. This shortfall also affects the development of spelling ability. That is, learners with insufficient phonemic awareness have difficulty in spelling or may not spell because they do not understand how letters match to sounds (Griffith \& Olson, 1992). In the same way, learners who do not possess phonemic awareness also have difficulty in writing because they do not recognize that words are made up of individual sounds and thus cannot understand how words are created (Dulude, 2012; Carello, Liberman, Lukatela \& Shankweiler, 1994).

It is apparent that phonemic awareness is very important for language skills acquisition and development because it enables learners to read, spell, and write familiar and unfamiliar words without memorizing (McCulloch, 2000). However, learners who do not possess adequate awareness cannot develop better language skills than those who do. Specifically, second language learners have to examine the phonological similarities and differences between their mother language and a second language. These differences are causes of confusion affecting the development of the phonemic awareness of second language.

Therefore, learners who have to learn another language may have more difficulty in perceiving, possessing, and developing phonemic awareness of second language than others. That is, the phonological differences between their mother tongue and second language can be a cause of confusion in acquiring, developing and possessing adequate phonemic awareness of second language because their mother tongue and second language might share phonological similarities. For example, native Japanese speakers have some confusion in perceiving, discriminating and pronouncing English phonemes / $\mathrm{I} /$ and /l/ because these sounds share phonological similarities to the Japanese phoneme / $/$. That is, when native Japanese speakers pronounce English phonemes $/ \mathrm{I} /$ and $/ \mathrm{l} /$, they always map English phonemes $/ \mathrm{x} /$ and $/ \mathrm{l} /$ to the Japanese phoneme / $/$ (Hayes-Harb \& Masuda, 2008). Thus, L2 learners might have difficulty in perceiving and developing phonemic awareness, and this difficulty influences language skills acquisition thereafter (Hayes-Harb \& Masuda, 2008; Justus, Mahurin, \& Robinson, 2011).

In Thailand, some Thai people also have difficulty perceiving, distinguishing, and pronouncing English phonemes because of the phonological differences between Thai and English. These differences affect Thai people in learning and developing English language skills. Many researchers have pointed out that the differences among consonant phonemes between Thai and English affect Thai learners in perceiving and discriminating English consonant phonemes (Brudhiprabha, 1964; Jotikasthira, 1995; Kanokpermpoon, 2007; Sarawit, 1997; Smyth, 2001). For example, Tubtimngam (1997) studied the problems, needs, and techniques for developing the required competencies of English teachers in Education Region 5 of Thailand and found that those teachers had difficulty in discriminating English phonemes from Thai phonemes (Potisompapwong, 2002). In other words, they could not examine and discriminate the similarities and differences between the phonemes of the two languages. In addition, over $91 \%$ percent of teachers in Tubtimngam's study had difficulty in teaching phonemic awareness of English to their students. Additionally, Sriprasit (2009) pointed out that Thai students also have problems with acquiring and developing phonemic awareness of English, thereby affecting English language skills acquisition (Ministry of Education [MOE], 2009).

The balanced literacy approach is a method that teaches phonemic awareness to learners and supports them in achieving adequate awareness. It combines whole language approach and phonics to teach skills such as word recognition and identification, fluency, vocabulary, and comprehension (Calais, 2008; Dombey, 2002; Donoghue, 2008; Tompkins, 2002). In other words, the balanced literacy approach is a combination of whole language approach and phonics (Cavkaytar et al., 2011). Tompkins (2002) provided seven general characteristics under the balanced literacy approach to teach literacy in classroom. First, literacy involving both reading and writing must be taught to learners at the same period. That is, learners are being read to and reading stories and writing at the same time. Second, literature is at the heart of this approach; therefore, teachers are expected to create a literature-rich environment to reinforce their student's exposure to various books. Third, language arts skills are taught both directly and indirectly. Fourth, reading instruction should involve learning word recognition and identification, vocabulary, and comprehension. Fifth, writing instructions should involve learning to express ideas, using spelling, grammar, and punctuation. Sixth, students utilize reading and writing as tools for learning in the content areas. Finally, the goal of the balanced literacy approach is to develop learners to be good readers and writers.

Consequently, the balanced literacy approach teaches learners to understand the relationship between letters and sounds along with text meaning and comprehension, thereby developing both phonemic awareness and understanding of word meaning. In addition, this approach also represents phonemic awareness, phonics, and word identification skills that balance the reading and writing of literature and other whole texts (Ramirez, 2005). Similarly, the balanced literacy approach may be a better and more selective approach in teaching literacy to learners as it provides them with opportunities to master the concept of print, learn the alphabetic system, acquire word recognition skills, develop phonemic awareness, involve themselves with reading and writing, and also experience a variety of appropriate materials in meaningful contexts (Zygouris-Coe, 2001). In other words, skills and language components are provided in 
situations where students can practice them. Notably, the balanced literacy approach also supports student-centered learning and teacher-directed learning, depending on the individual student's needs (Frey, Lee, Massengill, Pass, \& Tollefson, 2005).

For this study, the researchers studied the effectiveness of the balanced literayc approach in accelerating phonemic awareness of English among Thai first-grade students and investigated student engagement in learning phonemic awareness through this approach. It was designed to answer the following research questions: (A) do the students improve their phonemic awareness of English after traning through the balanced literacy approach? and (B) how are the students engaged in learnig phonemic awareness lessons through the balanced litearcy approach?

\section{METHOD}

\section{A. Participants}

Purposive sampling was used to select 30 students out of 400 first-grade students in Uttaradit province, Thailand, to participate in this study. Seventeen of them were female and 13 were male. This sample participated in the study for ten weeks. They were identified as having different levels of academic performance: low, moderate, and high.

\section{B. Procedure}

The phoneme discrimination tests were used as the pretest, the posttest, and the follow-up test for this study. The participants heard a word from a CD player twice and then identified and selected one answer choice that corresponded to the word. Pretesting was conducted in the first week before training. The pretest was given to evaluate the participants' ability to discriminate English phonemes. The results of the pretest determined the participants' phonemic awareness of English before the training program. After the training, the participants were given the posttest. Two weeks after the posttest, the participants were again given the tests as follow-up. The results of the posttest were compared with the pretest to determine whether the interventions could help the participants to discriminate English phonemes and develop their phonemic awareness of English. Additionally, the results gained from the follow-up test identified the participants' ability to retain and recall information about phonemic awareness from their memories.

TABLE I.

DURATION OF THE STUDY

\begin{tabular}{|l|l|l|}
\hline Period & Activities & Assessment types \\
\hline First week & Pretest & Test \\
\hline Second to fifth week & Study the phonemes /f/, /v/ & Practice and activities \\
\hline Sixth to ninth week & Study the phonemes /s, /z/ & Practice and activities \\
\hline Tenth week & Posttest & Test \\
\hline Two weeks after the posttest & Follow-up test & Test \\
\hline
\end{tabular}

\section{The Intervention Program Based on the Balanced Literacy Approach}

The intervention was divided into two phases: teaching and activities. The teaching process based on the balanced literacy approach focused on teaching the voiceless and voiced labio-dental fricatives (/f/ and /v/) and the voiceless and voiced alveolar fricatives (/s/ and /z/) positioning both of the initial and final consonants. The reason for choosing these four English fricative sounds was because these fricative sounds are problematic for Thai students to perceive, distinguish, and produce. Thus, if learners cannot perceive these sounds correctly, the process of distinguishing and pronouncing becomes more difficult (Brudhiprabha, 1964; Jotikasthira, 1995; Kanokpermpoon, 2007; Sarawit, 1997; Smyth, 2001).

At the beginning of each class period, the researchers read entire short stories or sang songs which contained the target sounds and words for the participants. After that, the researchers read or sang each sentence to the participants and then they were requested to repeat the reading or singing after the researchers. Then, the researchers translated the texts into Thai. The researchers showed flash cards with the letters corresponding to the sounds. Next, the researchers played the $\mathrm{CD}$ with the sounds corresponding to the letters on the cards three times. The participants were given mirrors and asked to pronounce the sounds. The researchers taught the participants how to pronounce the sounds. The words in the short stories or songs contained the target sounds presented on the flash cards with the pictures. On the flash cards, the target sounds were red, bold-faced, and underlined, while the other letters were black. For example, in the word "fan", the letter $\mathrm{f}$ is the target sound. After showing the cards, the researchers played the CD with the recorded words containing the target sounds three times. The participants followed and repeated the CD three times. The participants were given a worksheet with pictures on the right-hand side and words which were written along dotted lines on the left-hand side. The words on a worksheet were taught in each period. The participants wrote the words by joining the dots to form letters and coloring the pictures. After this writing practice, the participants played phonemic awareness activities.

Additionally, the researchers used activities to encourage participants to enjoy the class. The six activities administered in enhancing participants' phonemic awareness were as follows. 
Sound Identification: in this activity, the reserachers asked participants to answer questions that aimed to help participants detect sounds. For example, what was the first sound you heard in the word...? Or what was the final sound you heard in the word...? To answer these questions, the participants pronounced the sounds which they heard.

Same or Different: this activity supported participants in identifying and grouping phonemes as the same phoneme. The researchers pronounced two or three words and asked the participants to listen to the sounds of the words. After that, the researchers asked the participants whether those sounds which they heard were the same or different and they subsequently answered.

Fun with Sound Boxes: this activity was adapted from Elkonin Box, a type of instruction that teaches phonemic awareness by having students listen for individual sounds and marking where they heard them in the boxes. Each box on an Elkonin box card represents one phoneme or sound (Eldredge, 1995). The researchers gave a flash card prepared with a picture at the top of the card to the participants. Below the picture were squares for each phoneme. To practice the target sound, the square box for the target sound was left blank, while the other boxes were already filled in. Therefore, the participants needed to fill in the blank with the letter or letters to make a word.

Finding Graphemes: the researchers provided participants with pages from English books, newspapers, and magazines. The researchers pronounced sounds, and then the participants had to find and cut out the letters corresponding to the sounds in the books, newspapers and magazines provided.

Who am I?: the participants were provided with two cards. The first card had printed letters at the top of the righthand corner of the card with a picture of animal, object, or place at the center of the card. The other card without a picture had a printed letter at the top left-hand corner. Then, the participants had to place these cards together to form a word.

Crossword: a crossword is a word puzzle that normally takes the form of a square or a rectangular grid of white and shaded squares. The goal is to fill the white squares with letters, forming words or phrases, by solving clues which lead to the answers. The participants needed to complete a crossword by filling in letters that fitted each clue.

\section{Observation Form}

Video recording was used to observe student engagement while being taught phonemic awareness. Observation form was used to evaluate student engagement during class instruction, and the following characteristics were used an observation rubric to determine the engagement of students during class instruction: (a) eye contact, (b) behavior, (c) preparation, (d) listening, questioning, and discussing, (e) following directions, and (f) student confidence. Additionally, field notes were created by the researchers to remember and record student behavior in learning phonemic awareness. The data obtained from the video recording and field notes described how the students were engaged in learning phonemic awareness.

\section{E. Data Analysis}

A quantitative statistical analysis that focused on the development of the phonemic awareness of English was used to analyze the data. The data in this study were analyzed according to the research questions. The scores or data obtained were collected from the pretest, posttest, and follow-up test and analyzed by using mean and standard deviation. MANOVA was also used to find out whether there were significant differences between the scores gained from the pretest, posttest, and follow-up test. The qualitative data were derived from the analysis of the video recordings and field notes during the classroom teaching. The researchers used an observation rubric to determine the engagement of students during class instruction: (a) eye contact, (b) behavior, (c) preparation, (d) listening, questioning, and discussing, (e) following directions, and (f) student confidence. The qualitative data provided information about student engagement in learning phonemic awareness.

\section{RESULTS}

\section{A. Quantitative Results}

The results in terms of the initial consonant tests revealed that the mean score in the posttest was 13.20, with standard deviation of 1.37 , and the mean follow-up test score was 12.93 , with a standard deviation of 1.48 , whereas the mean pretest score was with $\mathrm{M}=8.37$ with $\mathrm{SD}=1.96$.

Students had scores in the posttest for the final consonant sounds with $\mathrm{M}=12.20$ and $\mathrm{SD}=1.58$ and also had scores in the follow-up test with $\mathrm{M}=12.03$ and $\mathrm{SD}=1.73$, compared to the mean pretest score $(\mathrm{M}=7.13, \mathrm{SD}=2.21)$. Table 2 presents the total scores of the initial and the final consonant tests. 
TABLE II.

THE MEAN AND STANDARD DEVIATION FROM

THE MEASURES OF PHONEMIC AWARENESS

\begin{tabular}{|l|l|l|l|}
\hline Variables & Period & M & SD \\
\hline \multirow{3}{*}{ Initial } & Pretest & 8.37 & 1.96 \\
\cline { 2 - 4 } & Posttest & 13.20 & 1.37 \\
\cline { 2 - 4 } & Follow-up test & 12.93 & 1.48 \\
\hline \multirow{3}{*}{ Final } & Pretest & 7.13 & 2.21 \\
\cline { 2 - 4 } & Posttest & 12.20 & 1.58 \\
\cline { 2 - 4 } & Follow-up test & 12.03 & 1.73 \\
\hline
\end{tabular}

With regard to the scores from the initial consonant tests, the posttest score was higher than the pretest at the .01 significance level (difference in scores $=4.83, \mathrm{SE}=.23, \mathrm{p}<.001$ ). Similarly, the follow-up score was also higher than the pretest at the .01 level of significance (difference in scores $=4.56, \mathrm{SE}=.25, \mathrm{p}<.001$ ). When comparing the posttest and the follow-up test score, it was found that the follow-up test score was lower than the posttest at the .05 significance level as shown in Table III.

TABLE III.

MULTIPLE COMPARISON OF

THE INITIAL CONSONANTS OVER TIME

\begin{tabular}{|l|l|l|l|l|}
\hline Time & $\mathrm{M}$ & Pretest & Posttest & Follow-up \\
\hline Pretest & 8.37 & & $4.83^{* *}$ & $4.56^{* *}$ \\
\hline Posttest & 13.20 & & & $-.27 *$ \\
\hline Follow-up & 12.93 & & & \\
\hline \multicolumn{5}{|c|}{$\begin{array}{c}\text { Note. } * \mathrm{p}<.05 . \\
* * \mathrm{p}<.01 .\end{array}$}
\end{tabular}

The results of the final consonant tests revealed that the posttest score was higher than the pretest at the .01 significance level. Additionally, it was found that the follow-up test score was statistically higher than the pretest at the .01 significance level. Analysis of the posttest and the follow-up test scores revealed that there were no significant differences between the posttest and the follow-up test scores as presented in Table IV.

TABLE IV.

MULTIPLE COMPARISON OF

THE FINAL CONSONANTS OVER TIIME

\begin{tabular}{|l|l|l|l|l|}
\hline Time & $\mathrm{M}$ & Pretest & Posttest & Follow-up \\
\hline Pretest & 7.13 & & $5.07 * *$ & $4.90^{* *}$ \\
\hline Posttest & 12.20 & & & -.17 \\
\hline Follow-up & 12.93 & & & \\
\hline \multicolumn{5}{|c|}{ Note. ${ }^{* *} \mathrm{p}<.01}$. \\
\hline
\end{tabular}

In order to better understand the scores from the initial and final consonant tests ganied from the participants, the following graph is plotted in Figure 1.

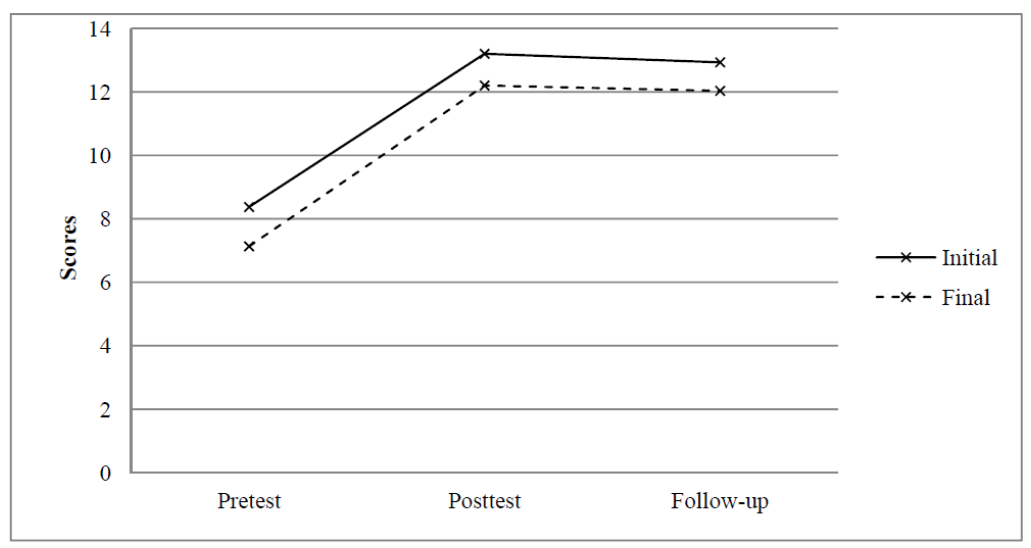

Figure 1. The pretest, posttest and follow-up scores for the Initial and final consonant tests

\section{B. Qualitative Results}

Video recording and field notes were used to record the participants' engagement and responses while being taught phonemic awareness.

Over the eight weeks of phonemic awareness training, observation data were collected and analyzed to assess the teaching approach. Students were also observed each time to obtain information about their behavior during training. Video recording and field notes were used to obtain information about students' responses. Students were defined as "engaged" during each teaching period if the researchers judged that they responded appropriately to the researchers' 
instructions during the entire period. Conversely, students were identified as "not engaged" if they responded inappropriately to the researchers' instructions.

The researchers used the following characteristics to determine the engagement of a student during class instruction: (a) eye contact, (b) behavior, (c) preparation, (d) listening, questioning, and discussing, (e) following directions, and (f) student confidence.

After analyzing observation data, it was found that the students taught using the balanced literacy approach were apparently engaged in learning phonemic awareness. That is, during class the students always paid attention and kept their attention on the researchers with direct eye contact as well as focusing on learning activities. Additionally, the students often demonstrated positive behaviors. In other words, they rarely displayed disruptive behaviors or distracted their peers from the learning process. While the researchers were teaching, the students also respectfully listened. Furthermore, they usually expressed their opinions, discussed with their peers to find out the answers, and also helped their peers in solving problems when participating in team-based work.

In addition, they could ask questions which were appropriate and related to the learning contents. The researchers also found that the students under the balanced literacy approach could follow classroom procedures; they appropriately followed and responded to the researchers' instructions without hesitation. In addition, the students usually prepared themselves for assignments; they always promptly worked on activities as assigned and requested by the researchers. That is, they exhibited interest and enthusiasm while working on their assignments in order to complete them before the end of class each time. Finally, the students showed that they had confidence to ask questions and complete the assigned tasks; they could generate questions with minimum assistance from the researchers.

\section{DisCUSSION}

This study clarifies the effects of the balanced literacy approach toward students' abilities in enhancing their phonemic awareness of English and it also provides information about student engagement in learning phonemic awareness lessons using the balanced literacy approach. According to the first question, the students using the balanced literacy could develop their phonemic awareness of English over the training period. They showed improvement in performances on phonemic awareness in the posttest, both for the initial and final consonant sounds. In other words, they attained higher scores in phonemic awareness in the posttest compared to the pretest. Similarly, they also showed that they understood phonemic awareness and performed better in the follow-up test, both for the initial and final consonants. That is, they obtained better scores in the follow-up test. This was because the balanced literacy approach supported students in practicing phonemic awareness of English so that they could develop it successfully.

The reason that the students under the balanced literacy approach could develop their phonemic awareness was that the method exposed students to the concept of print, the alphabetic system, and word recognition and also developed their phonemic awareness, got them involved with reading and writing, and provided them with experiences for learning in meaningful contexts (Zygouris-Coe, 2001). In the learning process, the researchers exposed the students to letter-sound correspondence embedded in the learning content such as in books, short stories, and songs. This supported the students to understand and practice their phonemic awareness of English in order that they could enhance it.

In addition, the results of the present study were also consistent with O'Day (2009), whose study reported on the effectiveness of the balanced literacy approach towards literacy instructional practices for English learners and nonEnglish learners. Her results revealed that the balanced literacy approach was effective in developing the phonemic awareness of both English learners and non-English learners and this approach also supported them in achieving learning literacy. The results revealed that the students instructed under the balanced literacy approach enhanced their phonemic awareness and also tended to advance their literacy skills. After the training period, the teachers informed the researcher that the students could read and write words faster than those who did not participate in the current study. In addition, they were also able to detect sounds better and faster. When they detected the sounds, they could match them upon hearing to the letters.

The second question concerned the qualitative data. The question was how the students were engaged in learning phonemic awareness lesson through the balanced literacy approach. According to the results of this study, the students were engaged with the learning process and participated actively in activities. The results were consistent with the research of Cavkaytar et al. (2011), in which various activities based on the balanced literacy approach encouraged students to be involved in class. The researchers observed that the students taught using this method in the current study were always excited to learn when the researchers introduced new stories and games to them. In essence, they were eager to know what the researchers would teach them in each period. In addition, the findings of the present study revealed that the students respectfully listened, discussed, and helped their peers to solve problems when working as a team. This supported them in practicing their communication skills; they were enthusiastic to discuss with their friends in order to answer questions. The results were consistent with the study constructed by O'Day (2009), in which students could take advantage of engaging in conversation and discussion in literacy, which provided practice for oral language development in a meaningful communication context.

In addition, most of the students under the balanced literacy approach responded to the researchers' instructions without hesitation. This might be due to the fact that the balanced literacy approach also supported student-centered learning and teacher-directed learning, depending on the individual student's needs (Frey, Lee, Massengill, Pass, \& 
Tollefson, 2005). In the current study, the researchers observed that the students were more relaxed when learning phonemic awareness as the researchers did not force them to engage in their activities without their willingness. Moreover, they also had the opportunity to choose the activities which they liked to learn through and do most.

\section{ACKNOWLEDGMENT}

The researchers gratefully acknowledge the teachers and students who participated in this study, without their cooperation this study could not be carried out.

\section{REFERENCES}

[1] Behan, S., Dunbar, C., Dunn, J., Ferguson, J., Gray, C., \& Mitchell, D. (2007). Developing young readers through the linguistic phonics approach. International Journal of Early Years Education, 5.1, 15-33.

[2] Bicăn, A. (2005). Phoneme in functional and structural phonology. Linguistica Online. Retrieved from http://www.phil.muni.cz/linguistica/art/bican/bic-001.pdf (accessed 7/2/2011).

[3] Bosman, A., Graaff, S., Hasselman, F., \& Verhoeven, L. (2009). Benefits of systematic phonics instruction. Science Studies of Reading, 13.4, 318-333.

[4] Brudhiprabha, P. (1964). A comparative study of difficult sounds in English for Thai speakers. Bangor, United Kingdom: University College of North Wales Press.

[5] Calais, G. (2008). Employing Siegler's overlapping waves theory to gauge learning in a balanced reading instruction framework. Focus on Colleges, Universities, and Schools, 2.1, 1-10.

[6] Carlson, C., Chen, D., Fletcher, J., Foorman, B., Francis, D., \& Moats, L. (2003). The necessity of the alphabetic principle to phonemic awareness instruction. Reading and Writing, 16, 289-324.

[7] Caravolas, M.,Hulme, C., \& Volín, J. (2005). Phoneme awareness is a key component of alphabetic literacy skills in consistent and inconsistent orthographies: Evidence from Czech and English children. Journal of Experimental Child Psychology, 92, 107- 139.

[8] Carello, C., Liberman, I. Y., Lukatela, K., \& Shankweiler, D. (1994). Phonological awareness in illiterates: Observations from Serbo-Croatian. Haskins Laboratories Status Report on Speech Research, 119.20, 39-57.

[9] Cavkaytar, S., Erdiken, B., Girgin, M. C., Gingin,U., Karasu, G., Kaya, Z., Tanridiler, A., \& Uzuner., Y. (2011). An examination of balanced literacy instructional model implemented to youths with hearing loss. Educational Sciences: Theory \& Practice, 11.4, 2126-2133.

[10] Deureen, D. V., \& Reading, S. (2007). Phonemic awareness: When and how much to teach. Reading Research and Instruction, 46.3, 267-286.

[11] Dombey, H. (2002). Towards a balanced approach to phonics teaching. Reading, 33.2, 52-58.

[12] Donoghue, M. (2008). Language arts: Integrating skills for classroom teaching. New York, NY: Sage Publications.

[13] Dulude, L. (2012). Writing system, phonemic awareness, and bilingualism: Cross-linguistic issues in dyslexia. Indiana University Undergraduate Journal of Cognitive Science, 7, 22-30.

[14] Eldredge, J. L. (1995). Teaching decoding in holistic classrooms. Englewood Cliffs, NJ: Prentice-Hall.

[15] Frey, B. B., Lee, S. W., Massengill, D., Pass, L., \& Tollefson, N. (2005). Balanced Literacy in an Urban School District. The Journal of Educational Research, 98.5, 272-280.

[16] Gillon, G. T. (2005). Facilitating phoneme awareness development in 3- and 4-year-old children with speech impairment. Language, Speech, and Hearing Services in Schools, 36, 308-324.

[17] Griffith, P. L. (1991). Phonemic awareness helps first graders invent spellings and third graders remember correct spellings. Journal of Reading Behavior, 23.2, 215-233.

[18] Griffith, P. L., \& Olson, M. W. (1992). Phonemic awareness helps beginning readers break the code. The Reading Teacher, 45.7, 516-523.

[19] Harm, H. M., Ross, C. L., \& Ukrainetz, T. A. (2009). An investigation of treatment scheduling for phonemic awareness with kindergartners who are at risk for reading difficulties. Language, Speech, and Hearing Services in Schools, 40, 86-100.

[20] Hayes-Harb, R., \& Masuda, K. (2008). Development of the ability to lexically encode novel second language phonemic contrasts. Second Language Research, 24.1, 5-33.

[21] Jotikasthira, P. (1995). Mastering the structure of English. Bangkok, Thailand: Chulalongkorn University Press.

[22] Justus, B., Mahurin, S. L., \& Robinson, G. C. (2011). Predicting difficulties in learning phonetic transcription: Phonemic awareness screening for beginning speech-language pathology students. Contemporary Issues in Communication Science and Disorders, 38, 87-95.

[23] Kanokpermpoon, M. (2007). Thai and English consonantal sounds: A problem or a potential for EFL learning?. ABAC Journal, 27.1, 57-66.

[24] McCulloch, M. T. (2000). Helping children learn phonemic and graphemic awareness. Retrieved from ERIC database. (ED439403) (accessed 3/8/2011).

[25] Ministry of Education. (2009). The role of the English clinic in the treatment of dyslexia in accordance with a new researchbased literacy framework in English language teaching in Thailand (with a focus on the teaching of phonemic awareness and phonics as a firm foundation for reading success). Retrieved from http://www.moe/th/news/detail.php?NewsID=6306\&Key=news2 (accessed 19/12/2011).

[26] O’Day, J. (2009). Good instruction is good for everyone - or is it? English language learners in a balanced literacy approach. Journal of Education for Students Placed at Risk, 14, 97-119.

[27] Potisompapwong, S. (2002). The development of CALL exercises for practicing the pronunciation of problem sounds in English for Mattayomsuksa Two students of Prapathomittayalai School, Nakornpathom (Master's thesis). Silpakorn University, Bangkok. 
[28] Ramirez, R. (2005). A case study inquiry into the relative impact of balanced reading instruction on Hispanic students in a highly culturally diverse elementary school (Doctoral dissertation). Louisiana State University, LA.

[29] Sarawit, E. M. (1997). English phonetics and phonology. Pitsanulok, Thailand: Naresuan University Press.

[30] Smyth, D. (2001). Learner English: A teacher's guide to interference and other problems. In B. Smith \& M. Swan (Eds.), Thai Speakers (pp. 343-356). Cambridge, United Kingdom: Cambridge University Press.

[31] Tankersley, K. (2003). Threads of reading: Strategies for Literacy Development. Alexandria, VA: Association for Supervision and Curriculum Development.

[32] Tompkins, G. E. (2002). Literacy for the $21^{\text {st }}$ century (3rd ed.). Upper Saddle River, NJ: Merrill Prentice Hall.

[33] Werker, J. F., \& Yeung, H. H. (2009). Learning words' sounds before learning how words sound: 9-month-olds use distinct objects as cues to categorize. Cognition, 113, 234-243.

[34] Yopp, H. K. (1992). Developing phonemic awareness in young children. The Reading Teacher, 45.9, 696-703.

[35] Zeece, P. D. (2006). Sound reading and reading sound. Early Childhood Education Journal, 34.2, 169-175.

[36] Zygouris-Coe, V. (2001). Balanced reading instruction in K-3 classrooms (Document \# 1-001.). Retrieved from http://flare.ucf.edu (accessed 5/12/2012).

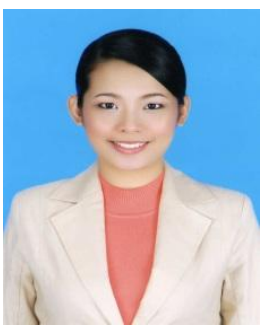

Sarunya Tarat is a lecturer at Naresuan University International College (NUIC), Naresuan University. Her interests involve phonology and students who are second-language learners

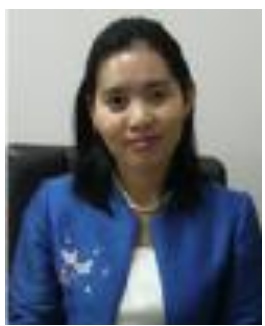

Usaporn Sucaromana (Ph.D.) is an assistant professor at Srinakharinwirot University in the Department of Western Languages, Faculty of Humanities. Her interests include applied linguistics, foreign language teaching, language testing, and psycholinguistics. 